\title{
Federalismo e políticas públicas: abrangências e convergências temáticas desse campo de estudos no Brasil
}

\author{
Federalism and public policies: the thematic scope and \\ convergences of this field of studies in Brazil
}

\author{
Gabriela Spanghero Lotta \\ Professora, Bacharelado em Políticas Públicas, \\ Programa de Pós-graduação em Políticas Públicas/Universidade Federal do ABC. \\ gabriela.lotta@ufabc.edu.br
}

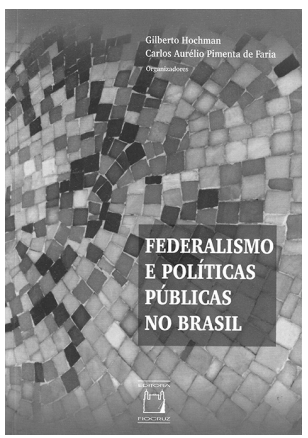

HOCHMAN, Gilberto; FARIA, Carlos Aurélio Pimenta de (Org.). Federalismo e políticas públicas no Brasil. Rio de Janeiro: Editora Fiocruz. 2012.
Tos últimos anos, a área de políticas públicas no Brasil tem tido 1 um grande crescimento, tanto em termos de cursos de formação (graduação e pós-graduação) como na produção científica (livros, artigos, congressos). Esse crescimento responde, em grande medida, à expansão da importância que o Estado tem ocupado na produção de políticas públicas pós-Constituição Federal de 1988. No entanto, como já aponta a literatura, até recentemente sabíamos muito pouco a respeito do Estado brasileiro - sua estrutura e funcionamento (Hochman, Arretche, Marques, 2007; Souza, 2006). O desenvolvimento recente da literatura tem se aprimorado em apresentar e analisar a complexidade de elementos que constituem e estão relacionados ao Estado brasileiro, considerando suas particularidades em termos históricos, institucionais e de atores envolvidos, bem como suas relações com o sistema político e com a sociedade.

Um dos temas relevantes ressaltados pela literatura nestes últimos anos é o do federalismo, que tem apresentado como variável importante para explicar o funcionamento do Estado e a produção de políticas públicas, especialmente após as inovações que a Constituição Federal de 1988 propôs ao desenho federativo brasileiro.

Ao longo das últimas duas décadas, o federalismo se tornou um tema caro tanto aos cientistas políticos mais tradicionais - buscando compreender aspectos político-partidários como para os analistas de políticas públicas - observando como as dinâmicas e resultados das politicas são condicionados pelo desenho e funcionamento do federalismo. Nos últimos anos, por exemplo, essa literatura já produziu autores consagrados e correntes analíticas em diversas discussões concernentes ao tema do federalismo, como, por exemplo, processos de centralização e descentralização, relações federativas, competências federativas, influência dos partidos nas dinâmicas federativas, entre outros. 
Essa mesma literatura tem cada vez mais apontado a interferência do federalismo nas políticas públicas, observando como o desenho e a dinâmica específicas do federalismo brasileiro são relevantes para compreender os resultados dessas políticas. No entanto, embora a literatura reconheça a relação entre federalismo e políticas públicas, esse é um campo que ainda merece bastante aprofundamento, seja em termos de estudos setoriais, seja na análise de casos específicos ou na identificação de padrões processuais que se vêm constituindo no recente período pós-1988.

É na contribuição a esse campo que se situa a recente publicação de Federalismo e políticas públicas no Brasil (organizado por Gilberto Hochman e Carlos Aurélio Pimenta de Faria). O livro busca "divulgar estudos que têm o potencial de redirecionar as pesquisas na área, contribuir para o seu fortalecimento no campo de análise de políticas públicas no Brasil" (p.11). Os 12 trabalhos que o compõem foram selecionados, em parte, de artigos integrantes do Grupo de Trabalho de Políticas Públicas da Associação Nacional de Pós-Graduação e Pesquisa em Ciências Sociais (Anpocs), coordenado pelos organizadores do livro entre 2007 e 2009, e, em parte, encomendados a reconhecidos especialistas na discussão de federalismo que, ou escreveram textos originais, ou revisaram e atualizaram artigos já publicados. E, como afirmam os organizadores na apresentação, "reunidos em livro, esses artigos ganharam novos sentidos e promovem inovadores e originais diálogos com a produção intelectual em políticas públicas" (p.11).

A obra é organizada em quatro partes, cada uma com três capítulos de diferentes autores e que guardam em comum, em grande medida, apenas os grandes temas abordados, visto que o recorte do objeto, a seleção de variáveis e metodologias variam internamente às partes.

A primeira delas busca compreender o processo de constituição e reforma do federalismo brasileiro. Nesse sentido, o federalismo se torna o objeto a ser explicado, compreendido por meio de análise comparativa das suas instituições (Rocha), por meio das regras que alteram a dinâmica do processo decisório (Arretche) ou por meio da produção de regras que alteram o próprio desenho do federalismo (Souza).

A segunda parte busca compreender as interfaces entre federalismo, competição eleitoral e políticas públicas. Para tanto, os artigos se valem de análise das regras do federalismo e do sistema político para compreender o desenho das políticas públicas (Borges), da análise do impacto das regras do federalismo e da dinâmica partidária e suas consequências para a dinâmica das políticas públicas (Ribeiro) e da análise do modo como as regras do federalismo, entre outras variáveis, impacta o processo de difusão de políticas públicas (Coelho).

A terceira parte é voltada para o tema da cooperação intergovernamental, buscando compreender como o desenho federativo brasileiro incentiva ou constrange ações de coordenação (Faria e Machado; Machado) e, por outro lado, como incentivos e punições podem e são estabelecidos para induzir mais coordenação e cooperação entre as partes (Sano e Abrucio; Machado).

A quarta e última parte analisa aspectos específicos de políticas setoriais, com ênfase em saúde, assistência social e educação. Os textos buscam analisar as relações entre políticas e federalismo, compreendidas como processos que se desenvolvem no tempo e no espaço (Hochman) e que são influenciadas por desenhos, mecanismos institucionais e comportamentos 
específicos que impactam a coordenação e descentralização (Costa e Palotti, Franzese e Abrucio).

Embora o federalismo seja o objeto comum que une todos os capítulos, o livro é marcado por uma grande diversidade - o que, por si só, já é uma das riquezas para os leitores que buscam adentrar o campo das discussões sobre federalismo. É, podemos dizer, quase um "mapa da mina" a respeito do que se tem produzido no Brasil sobre o tema nos últimos anos. Isso porque, como já se ressalta no objetivo acima apontado, o livro apresenta múltiplas perspectivas analíticas sobre o federalismo. Nesse sentido, além de conhecer múltiplas formas de se olhar para esse objeto, o leitor será apresentado a diferentes metodologias (qualitativas e quantitativas, e com técnicas variadas); diferentes enfoques analíticos (análise de instituições, análise histórica, análise de atores); distintos casos (análise de municípios, regiões metropolitanas, governos estaduais e federal, e análise comparada de diferentes governos federais); distintos setores (educação, saúde, assistência social, transferência de renda) e, especialmente, diferentes conclusões sobre a relação entre políticas públicas e federalismo.

Além disso, há diversidade inclusive na maneira como se busca analisar o federalismo: embora, na maioria dos capítulos, ele apareça como uma variável explicativa para os resultados ou dinâmicas das políticas públicas, em alguns textos o próprio federalismo é apresentado como a variável dependente, explicada por outros condicionantes históricos ou institucionais. Desse trabalho se conclui o quanto o desenho federativo brasileiro é único e diferenciado, ao contrário do que a literatura internacional sugeria como resultados esperados a partir de seu desenho.

Em seu conjunto, são basicamente três as questões que todos os capítulos buscam responder, embora com enfoques e graus distintos: (1) quais as características específicas do federalismo brasileiro - não apenas em termos de regras formais, mas também de atores que o compõem e dinâmicas que lhe dão vida; (2) que fatores explicam as origens e alterações desse desenho específico de federalismo brasileiro; (3) quais as consequências dessas características para as dinâmicas e os resultados das políticas públicas.

E é nas distintas formas de responder a essas questões que Federalismo... prima por apresentar ao leitor um profundo e variado panorama dos estudos sobre o tema no Brasil. Ao final do livro, o leitor poderá chegar a interessantes conclusões tanto a respeito do desenho e funcionamento do federalismo brasileiro como da literatura nacional - questões essas que sinalizam relevantes pontos para uma agenda futura de pesquisas.

Com relação ao federalismo brasileiro, o leitor terá como conclusão - e essa é uma das maiores contribuições do livro - que a compreensão dos resultados das políticas públicas prescinde de uma análise do desenho e da dinâmica do federalismo brasileiro (tanto elementos mais gerais como setoriais). A segunda grande conclusão é de que o oposto também é verdadeiro, ou seja, se não dá para entender os resultados das políticas sem olhar para o desenho federativo, também não dá para entender o desenho e o funcionamento do federalismo brasileiro sem compreender a natureza e a história das políticas públicas.

Nesse sentido, conclui-se, de forma geral, a partir do livro, que o "federalismo brasileiro" não é uma categoria estanque: ela se concretiza de diferentes formas, considerando-se as especificidades de cada setor, política ou momento histórico. E isso pode ser observado analisando-se as regras diversas, a história, a dinâmica dos atores e a dinâmica do sistema 
político eleitoral. Essas múltiplas possibilidades analíticas são, inclusive, parte importante das conclusões da obra.

Com relação às contribuições que o livro traz para a literatura, em primeiro lugar, ficará clara ao leitor a importância da construção de uma literatura nacional a respeito do federalismo, que analise suas características específicas e diferenciadas de outros modelos existentes no mundo. Como apontam alguns dos capítulos, embora a literatura internacional sobre o funcionamento dos sistemas federativos já tenha avançado em traçar comparações amplas e derivar as consequências das especificidades, há algumas características presentes no desenho e na dinâmica federativa brasileira que devem ser vistas cuidadosa e especificamente. Dessa conclusão se deriva uma agenda de pesquisas a ser ainda complementada no Brasil: a análise de mais setores, casos e enfoques específicos, que, em seu olhar de conjunto, permita à literatura nacional extrair retratos mais abrangentes e aprendizados gerais a respeito das especificidades brasileiras, em comparação a casos e à literatura internacional.

Em segundo lugar, o livro permite perceber que o campo de estudos sobre federalismo é amplo e vasto, mas ainda tem potencial para desenvolvimento de estudos originais. Isso porque, como se demonstra pela somatória de capítulos, as abordagens ainda são muito distintas entre si, permitindo que se explorem as interconexões entre elas e, ao mesmo tempo, especificidades de campos e setores que ainda foram pouco analisados pela literatura. Se, por um lado, alguns capítulos primam por realizar análises abrangentes e tirar conclusões mais gerais sobre o desenho e funcionamento do federalismo brasileiro, por outro lado, há capítulos que mostram que a análise das especificidades setoriais ou em relação a entes federativos é imprescindível para uma compreensão mais acurada do campo. Essa percepção é também mais uma contribuição à construção da agenda nacional de estudos do federalismo: o aprofundamento e complementação de estudos específicos e sua convergência em análises mais gerais.

Em terceiro lugar, percebe-se que há um potencial analítico ainda a ser aprofundado por estudos que analisem o federalismo numa perspectiva histórica mais ampla. Embora a Constituição Federal de 1988 seja um marco central para compreensão do desenho e funcionamento atual do federalismo, alguns dos trabalhos presentes no livro demonstram que a compreensão do momento atual só pode ser explicada olhando-se para períodos anteriores à Constituição. Trazer essa visão histórica mais abrangente é um ponto fundamental à literatura nacional, especialmente aos estudos ainda voltados para analisar casos específicos olhando apenas para o período pós-1988.

Em quarto lugar, fica evidente que a análise das instituições é um ponto fundamental para os avanços de estudos sobre o federalismo na literatura nacional. No entanto, como alguns dos capítulos demonstram, também é evidente a importância de integrar outros elementos e fatores à análise do federalismo - como fatores simbólicos, fatores político-eleitorais, análise de atores etc. - elementos que se tornam centrais para o aprimoramento da agenda nacional de estudos sobre o tema.

Como se pode perceber a partir da leitura do livro e de uma análise dos trabalhos sobre federalismo no Brasil, embora esse campo já tenha um importante e reconhecido acúmulo de estudos, há ainda um grande potencial a ser desenvolvido, fruto da própria complexidade do objeto analisado - o federalismo - e das múltiplas facetas nas quais ele se concretiza nas 
políticas públicas brasileiras. A diversidade contida no livro apenas reflete a diversidade analítica desse objeto e seu potencial para ser explorado nas mais diversas abrangências, perspectivas e metodologias. Assim, ao mesmo tempo em que o federalismo se apresenta como um profícuo objeto, com elementos ainda a explorar, tem sua importância reforçada, dada sua capacidade já reconhecida de interferir e explicar resultados de políticas públicas.

\section{REFERÊNCIAS}

HOCHMAN, Gilberto, ARRETCHE, Marta; MARQUES, Eduardo (Org.).

Políticas públicas no Brasil. Rio de Janeiro: Ed. Fiocruz. 2007.
SOUZA, Celina.

Políticas públicas: uma revisão da literatura. Sociologias, n.16, p.20-45. jul.-dez. 2006. 